\title{
The Efficacy of the Water Purification System with an Ultra Violet Lamp and Ultrafilter for the Preparation of Bovine Embryo Culture Media
}

\author{
Masashi NAGANO, Yoshiyuki TAKAHASHI and Seiji KATAGIRI \\ Laboratory of Theriogenology, Department of Veterinary Clinical Sciences, Graduate \\ School of Veterinary Medicine, Hokkaido University, Sapporo 060-0818, Japan
}

\begin{abstract}
The efficacy of a water purification system including a high-intensity $185 \mathrm{~nm}$ ultra violet lamp with ultrafilter (UV-UF) for eliminating endotoxins was examined. The activity of endotoxins was below the detectable level in UV-UF water. In contrast, ultra-purified water from a system without a UV lamp (UP) showed a high level of endotoxins, despite water resistivity of more than $18 \mathrm{M} \Omega \cdot \mathrm{cm}$. Bovine IVM/IVF zygotes were cultured for $174 \mathrm{~h}$ in protein-free media prepared with UV-UF and UP water. The developmental rate to blastocysts at $150 \mathrm{~h}$ was significantly higher in the medium prepared with UV-UF water. The results demonstrate that the UV-UF system is beneficial for eliminating endotoxins from ultra-purified water, and for preparing protein-free media for culture of bovine embryos.
\end{abstract}

Key words: Bovine, Embryo, Endotoxin, Water quality.

(J. Reprod. Dev. 45: 239-242, 1999)

$\boldsymbol{W}$ ater is a major component of embryo culture medium, and high-quality water is necessary for its preparation [1-4]. It is recommended to prepare culture media using reverse-osmosis ( $\mathrm{RO})$, deionized and ultra-filtrated water with a resistivity of at least $18 \mathrm{M} \Omega \cdot \mathrm{cm}$ [5]. However, it has been demonstrated that the water ultra-purified with a resistivity of more than $18 \mathrm{M} \Omega \cdot \mathrm{cm}$ contains some organic carbons, endotoxins and planktonic bacteria $[6,7]$. Endotoxins in the media suppress the embryonic development in mice [8-11] and in the human $[12,13]$. UV irradiation in the water purification system reduces the planktonic bacteria population in the system, and decreases the concentrations of total organic carbons and endotoxins in the purified water [6]. Further reduction in the concentrations of total organic carbons and endot-

Accepted for publication: February 12,1999

Correspondence: M. Nagano oxins can be expected by the addition of an ultrafilter located downstream from the UV lamp, since endotoxins are relatively large molecules.

The present study evaluated the efficacy of a water purification system including a UV lamp with an ultrafilter for the elimination of endotoxins. Moreover, bovine embryonic development was determined by culturing embryos using proteinfree media prepared with water from the above system, since there is no report which studies the effect of endotoxins on the development of bovine embryos using protein-free media.

\section{Materials and Methods}

Water for media preparation

We prepared ultra-purified water using the following two water purification systems (Fig. 1): UV-UF; The system had a four-cartridge purifica- 
tion pack (Q-pack; Nihon Millipore Ltd., Tokyo, Japan), which included activated-carbon and ionexchange resins housed within 4 cylinders, a high-intensity $185 \mathrm{~nm}$ UV lamp plus a polishing cartridge (Milli-Q SP TOC, Nihon Millipore) with an ultrafilter (Nihon Millipore) to remove organic carbons. This system was provided with water purified by a Milli-RX 12 Plus (RO-treated and deionized water, Nihon Millipore). UP; The system included an ultrafilter, ion-exchange fibers, and was provided with RO-treated and deionized water. The function of this system was equivalent to that of Q-pack. A final filter (pore size, $0.22 \mu \mathrm{m}$ ) was also a part of the system at the dispensing point of both units. Water provided from both systems showed resistivity of more than $18 \mathrm{M} \Omega \cdot \mathrm{cm}$. Total organic carbons in UV-UF water were analyzed with an A-100P portable analyzer (Anatel Co. Ltd., Colorado, USA). Endotoxin activities of the water from the two systems were determined using a Toxicolor endotoxin kit (Toxicolor system LS-6 Set; Seikagaku Co. Ltd., Tokyo, Japan). Endotoxin from Escherichia coli 0111:B4 (Seikagaku Co. Ltd.) was used as the standard.

\section{Source of zygotes}

Bovine zygotes were obtained after in vitro maturation and fertilization as described elsewhere [14]. In brief, bovine cumulus-oocyte complexes (COCs) from small antral follicles of abattoir ovaries were cultured for about $22 \mathrm{~h}$ in a Hepes-buffered TCM 199 (Gibco Laboratories, Grand Island, NY, USA) supplemented with fetal calf serum, follicle-stimulating hormone, estradiol-17 $\beta$, sodium pyruvate and gentamicin sulfate. In vitro fertilization was conducted using frozen semen from a Holstein bull. The motile sperm were separated using a discontinuous gradient with 45 and $90 \%$ Percoll (Pharmacia BioProcess, Uppsala, Sweden). The COCs were co-incubated with sperm at the concentration of $5 \times 10^{6} \mathrm{cell} / \mathrm{ml}$ in $100-\mu$ droplets of modified Brackett and Oliphant isotonic medium (mBO medium) containing fattyacid free BSA and theophylline covered with paraffin oil at $39 \mathrm{C}$ in a humidified atmosphere of $5 \% \mathrm{CO}_{2}, 5 \% \mathrm{O}_{2}$ and $90 \% \mathrm{~N}_{2}$. We used UV-UF water to prepare $\mathrm{mBO}$ medium. After $18 \mathrm{~h}$ of coincubation, presumptive zygotes were stripped of cumulus cells by vortexing in Hepes-buffered Tyrode's medium.
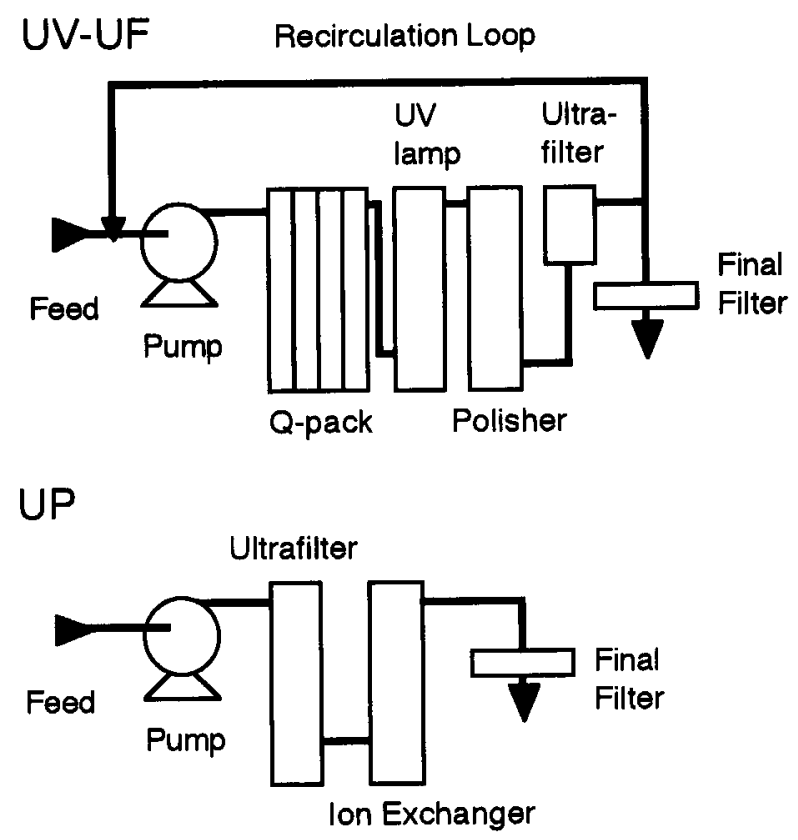

Fig. 1. Diagrams of the water purification systems. UV-UF: The system had a four-cartridge purification pack (Q-pack), a high-intensity $185 \mathrm{~nm}$ UV lamp plus a polishing cartridge and an ultra filter. UP: The system included an ultrafilter and ion-exchange fibers. The function of this system was equivalent to that of the Q-pack.

\section{In vitro culture of zygotes}

A modified synthetic oviduct fluid supplemented with 20 amino acids, $10 \mu \mathrm{g} / \mathrm{ml}$ insulin and 1 $\mathrm{mg} / \mathrm{ml}$ polyvinyl alcohol (mSOFai) [14] was used as a protein-free medium. Cumulus-free zygotes were cultured for another $174 \mathrm{~h}$ in $40-\mu \mathrm{l}$ droplets (about 40 zygotes per droplet) of the protein-free culture medium prepared with UP or UV-UF water covered with paraffin oil at $39 \mathrm{C}$ in a humidified atmosphere of $5 \% \mathrm{CO}_{2}, 5 \% \mathrm{O}_{2}$ and $90 \% \mathrm{~N}_{2}$. Embryonic development was evaluated at 150 and 174 $h$ of culture in the protein-free media.

\section{Results and Discussion}

Endotoxins were below the detectable level $(<0.001 \mathrm{EU} / \mathrm{ml})$ in UV-UF water, but were detected in UP water $(0.225 \mathrm{EU} / \mathrm{ml}=78 \mathrm{pg} / \mathrm{ml})$. UV-UF water contained a low level $(2 \mu \mathrm{g} / 1)$ of total organic carbons. Although the concentration of total organic carbons in UP water was not measured, 
Table 1. Development of bovine zygotes in protein-free media prepared with ultrapure water from two different types of water purification system

\begin{tabular}{lccc}
\hline \multicolumn{1}{c}{ Item } & \multicolumn{3}{c}{ Water source } \\
& & UP a) & UV-UF a) \\
\hline $\begin{array}{l}\text { No. of replicates (No. of oocytes) } \\
\text { \% of cleavage }\end{array}$ & $6(213)$ & $6(220)$ \\
$\%$ of blastocysts at & $150 \mathrm{~h}$ & $78.8 \pm 5.6$ & $80.0 \pm 4.0$ \\
& $174 \mathrm{~h}$ & $31.8 \pm 11.8$ & $\left.26.4 \pm 6.3^{\mathrm{d}}\right)$ \\
$\%$ of hatching rate b) at & $174 \mathrm{~h}$ & $22.3 \pm 19.0$ & $38.6 \pm 2.7$ \\
\hline
\end{tabular}

$\%$ Values are means \pm SD.

a) See Fig. 1 .

b) \% based on the number of blastocysts.

c, d) Values with different superscripts differ significantly $(p<0.05)$.

UP water should contain a higher level of total organic carbons than UV-UF water, since there is a positive correlation between total organic carbon contents and endotoxins concentration [6]. It was not clear why UP water showed such a high activity of endotoxins. In the conventional water purification system without a UV-UF unit, the contamination with a high level of endotoxins in the source water and the bacterial growth in a water purification system result in the high activity of endotoxins in the ultra-purified water [6]. The endotoxins activity in the source water for the UP system was over the measurable range of the Toxicolor endotoxin kit even after 11-times dilution. Whereas the activity of endotoxins was not detected in UV-UF water, in spite of the source water for the UV-UF system was contaminated with endotoxins at the activity beyond the measurable range. These results suggested the efficiency of the UV-UF system in the elimination of endotoxins. Further it is highlighted that the importance of routine evaluation of total organic carbons and/ or endotoxins in ultra-purified water derived from water purification systems without a UV-UF unit, even if they could provide an ultra-purified water with the resistivity of more than $18 \mathrm{M} \Omega \cdot \mathrm{cm}$.

There were no differences in the proportions of cleaved zygotes and hatching blastocysts between the two media (Table 1). However, the developmental rate of embryos to blastocysts at $150 \mathrm{~h}$ of culture was significantly higher in the medium prepared with UV-UF water than in the medium prepared with UP water $(\mathrm{P}<0.05$; Student's $t$-test). Same tendency $(\mathrm{P}=0.10$; Student's $t$-test $)$ was seen in the percentages of blastocyst at $174 \mathrm{~h}$ of culture. These results demonstrated that UV-UF water was suitable for preparing protein-free media for cul- ture of bovine embryos. This may be due to the lower activity of endotoxins in UV-UF water. Endotoxin contamination was reported not to affect the in vitro development of bovine embryos when they were co-cultured with somatic cells in medium containing serum [15]. In the presence of somatic cells and proteins, the detrimental effects of endotoxin might be eliminated [16]. As we used protein-free media, we could make the effect clear.

A reduction in the pregnancy rates has been demonstrated after the transfer of human embryos cultured in media containing relatively low concentrations $(1 \mathrm{pg} / \mathrm{ml})$ of endotoxins $[12,13,17]$, without a reduction in blastocyst formation rate [17]. Thus, it is likely that the pregnancy rate decreases after the transfer of bovine embryos cultured in the medium prepared with UP water due to a high level $(78 \mathrm{pg} / \mathrm{ml})$ of endotoxins. Further studies are needed to determine the dose-dependent effects of endotoxins on the in vitro development of bovine embryos and on their subsequent development in vivo after being transferred to the recipient animals.

It is concluded that the UV-UF system is beneficial to the elimination of endotoxins from ultra-purified water, and to the preparation of protein-free media for in vitro culture of bovine embryos.

\section{Acknowledgments}

This study was supported by a Grant-in-Aid for Scientific Research (No. 09660295) from the Ministry of Education, Science, Sports and Culture, Japan to Y. Takahashi. We thank the Nihon Millipore Ltd. for providing the Milli-Q SP TOC water puri- 
fication system with an ultrafilter, the Hokkaido Livestock Improvement Association for the donation of frozen bull sperm and the Ebetsu Meat
Inspection Office for the collection of bovine ovaries.

\section{References}

1. Bavister BD, Andrews JC. A rapid sperm mortility bioassay procedure for quality-control testing of water and culture media. J Vitro Fert Embryo Transfer 1988; 5: 67-75.

2. Fukuda A, Noda Y, Tsukui S, Matsumoto H, Yano J, Mori T. Influence of water quality on in vitro fertilization and embryo development for the mouse. J Vitro Fert Embryo Transfer 1987; 4: 40-45.

3. Nagao Y, Saeki K, Hoshi M, Takahashi Y, Kanagawa $\mathbf{H}$. Effects of water quality on in vitro fertilization and development of bovine oocytes in protein-free medium. Theriogenology 1995; 44: 433444.

4. Whittingham DG. Culture of mouse ova. J Reprod Fertil Suppl 1971; 14: 7-21.

5. Boatman DE. In vitro growth of non-human primate pre- and peri- implantation embryos. In: Bavister BD (ed.), The Mammalian Preimplantation Embryo. New York: Plenum Press; 1987; 273-308.

6. McFeters GA, Broadaway SC, Pyle BH, Egozy Y. Distribution of bacteria within operating laboratory water purification systems. Appl Enviro Microbiol 1993; 59: 1410-1415.

7. Mittelman MW. Biological fouling of purified-water systems: Part I, Bacterial growth and replications. Microcontamination 1985; 3: 51-70.

8. Dubin NH, Bornstein DR, Gong Y. Use of endotoxin as a positive (toxic) control in the mouse embryo assay. J Assist Reprod Genet 1995; 12: 147152.

9. Dumoulin JCM, Menheere PPCA, Johannes LHE, Kleukers APG, Pieters MHEC, Bras M, Geraedts JPM. The effects of endotoxins on gametes and pre- implantation embryos cultured in vitro. Hum Reprod 1991; 6: 730-734.

10. Montoro L, Subias E, Young P. Detection of endotoxin in human in vitro fertilization by the zona-free mouse embryo assay. Fertil Steril 1990; 54: 109-112.

11. Nagata Y, Yoshimitsu K, Ikeda K, Koyama M, Shirakawa K. Harmful effects of endotoxins in medium on fertilization in vitro of mice. J Fertil Implant 1992; 9: 190-193 (In Japanese).

12. Fishel S, Jackson P, Webster J, Faratian B. Endotoxins in culture medium for human in vitro fertilization. Fertil Steril 1988; 49: 108-111.

13. Snyman E, Van der Merwe JV. Endotoxin-polluted medium in human in vitro fertilization program. Fertil Steril 1986; 46: 273-276.

14. Takahashi Y, Hishinuma M, Matsui M, Tanaka H, Kanagawa H. Development of in vitro matured/ fertilized bovine embryos in a chemically defined medium: influence of oxygen concentration in the gas atmosphere. J Vet Med Sci 1996; 58: 897-902.

15. Madison V, Greve T, Avery B, Wamberg T. The effect of endotoxin-contaminated medium on in vitro fertilization and development of bovine oocytes matured in vitro. Reprod Nutr Dev 1991; 31: 159-165.

16. Flood LP, Shirley B. Reduction of embryotoxicity by protein in embryo culture media. Mol Reprod Dev 1991; 30: 226-231.

17. Nagata Y, Shirakawa K. Setting standards for the levels of endotoxin in the embryo culture media of human in vitro fertilization and embryo transfer. Fertil Steril 1996; 65: 614-619. 